\title{
Mordersi la lingua. Corrección política y posverdad
}

\author{
Darío Villanueva
}

PUBBLICATO: 31 MARZO 2021

$\mathrm{E}$ n mi lengua materna, morderse la lengua significa, según el diccionario académico, "contenerse en hablar, callando con alguna violencia lo que quisiera decir". Lo mismo también se puede expresar con "atarse la lengua"; en Cuba, sujetarse o tragarse la lengua. Tal autocontrol es difícil para los que tienen la lengua larga o muy larga, son ligeros de lengua o simplemente tienen mucha lengua, le dan mucho a la lengua o, no digamos, echan sin tasa la lengua al aire e incurren en el vicio de irse de la lengua, de dejar que se les escape la lengua. Como consecuencia, no es imposible que los tales lenguaraces tengan en algún momento que meterse la lengua en el culo. Es decir (más finamente): morderse la lengua. Mordersi la lingua.

No solo los hispanohablantes pasamos por ese trance de mordernos la lengua, sino que es servidumbre compartida por los italianos y en otros pagos. En inglés to bite one's tongue (o también one's lips) significa igualmente dejar de decir algo, incluso parando en seco, cuando te das cuenta de que sería una declaración inconveniente. Para los franceses, existe asimismo se mordre la langue, y sobre todo en el portugués de Brasil se da con el mismo significado morder a lingua (en Portugal es preferida la expresión meter-se em copas). Tampoco es ajena la expresión a la lengua china, según mis informantes nativos, como el modismo culto “粠舌缄唇” que incluye labios, además de la obligada mención a la lengua.

Pero si esta locución no solo española sirve, creo que muy cabalmente, para describir la exigencia fundamental de lo que en inglés se ha dado en llamar political correctness, la "corrección política" aplicada como una suerte de "higiene verbale" según Edoardo Crisafulli (y antes, en inglés, según Deborah Cameron), la post-truth de los anglosajones, nuestra "posverdad" (o "post-verità") nos suscita inmediatamente el recuerdo de otra de las acunaciones populares del castellano: comulgar con ruedas de molino. No sé encontrar algo parecido en italiano. Pero nosotros también usamos para tal fin expresivo el verbo tragar una mentira; esto es, admitir que "l'ho bevuta".

Es unánimemente reconocido por todos los que se han ocupado de la corrección política (en Italia, entre otros, Luigi Pintor) que su origen estuvo en los campus norteamericanos a partir de los años ochenta del pasado siglo. Desde ellos, descritos de manera implacable por el historiador Alfredo Jocelyn-Holt en el diario chileno La Tercera (el 3i de agosto de 20ig) como lugares doctos pero desde aquel entonces asediados por un sectarismo puritano procedente, sobre todo, de departamentos de Humanidades en franca decadencia, la corrección política se ha extendido a modo de un virus implacable al conjunto de la sociedad dentro y fuera de los Estados Unidos, inficionando la información, las relaciones personales y profesionales, la creación y las expresiones artísticas incluso.

Pero soy de la idea de que la posverdad tampoco es ajena a esa influencia, bastante insólita y poco común por otra parte, de la Universidad. Cierto que el presidente Donald Trump se convirtió en el catalizador ecuménico de la post-truth, de la que oficiaba como sumo sacerdote gracias a la catarata diaria de sus tuits y de sus declaraciones públicas en las que, desde su toma de posesión en enero de 2017, los rastreadores de mentiras políticas le han llegado ya a atribuirle más de veinte mil. Pero no puedo por menos que relacionar ese desprecio absoluto hacia la veracidad de los enunciados con el asombroso triunfo intelectual de la llamada French Theory que François Cusset (2003) ha estudiado 
detalladamente en su libro sobre las mutaciones de la vida intelectual en Estados Unidos.

Yo también soy de la creencia de que la llamada Deconstrucción de Jacques Derrida y las teorías de Foucault, Deleuze \& Cia. -como los llama Cusset-son responsables del auge de la posverdad, pues los gurús franceses del "pensiero debole" destruyeron la solvencia del lenguaje en cuanto portador de sentidos, caricaturizándolo como una algarabía de ecos, un discurso "told by an idiot, full of sound and fury, signifying nothing", en palabras del Macbeth de William Shakespeare (no de Jacques Derrida).

No me cabe duda, tampoco, de que posverdad y corrección política representan otros tantos síntomas de época, de la llamada Posmodernidad, y que deben ser estudiadas y comprendidas a la luz de los nuevos tiempos que desde el tránsito entre los dos milenios han dado lugar a una nueva sociedad globalizada de la información y la comunicación, resultante de una profunda transformación debida sobre todo al desarrollo de la tecnología digital: la Galaxia Internet.

Uno de los mantras de la corrección política es que decir algo es crear algo. Pero las palabras no crean: son creadas. Consisten en una construcción fonética estructurada en eslabones -sonido, sílaba, palabra- cuyo acoplamiento a una referencia -el objeto, hecho o realidad que se quiere designar- se basa en el principio de la arbitrariedad. El funcionamiento operativo de las referencias depende, pues, de un acuerdo o contrato social. Hoy estamos muy lejos ya de una teoría empírica del lenguaje como la que John Locke formulara en I69o, y que en lo sustancial llegó al primer Wittgenstein del Tractatus (I92I), según la cual las palabras resultan ser imágenes directas de la realidad, de las cosas percibidas a través de los sentidos.

Para poner en solfa esta "falacia referencial" a la que se referirá, pasando los siglos, Umberto Eco, el escritor satírico irlandés Jonathan Swift (I726) hace que Lemuel Gulliver, en uno de sus viajes que lo lleva a Balnibarbi, una isla del Pacífico norte entre Japón y California, conozca un bizarro proyecto que tienen en mente los miembros de la Academia de Lagado.

En su escuela de idiomas, aquellos arbitristas pretenden suprimir completa y absolutamente las palabras, pues su uso debilita los pulmones de los hablantes y, en consecuencia, reduce sus respectivas esperanzas de vida.

La solución que encuentran es de una sencillez abrumadora (y nunca mejor aplicado el adjetivo): como las palabras son simplemente nombres de cosas, lo más práctico sería que todos llevaran encima las cosas que necesitaran para expresarse. Los sabios ideadores de tal revolución -pensada, por supuesto, "para mayor comodidad y salud del individuo"- contaban con la oposición inicial de la plebe, empecinada en seguir hablando en su lengua materna, pero para paliar la evidente incomodidad del nuevo procedimiento proponían el recurso de una buena cohorte de criados encargados de transportar las cosas necesarias para mantener una conversación sabrosa. En todo caso, el esfuerzo valdría la pena, habida cuenta del mayor beneficio del invento: el triunfo, al fin, de un idioma universal, válido para el entendimiento entre sí de todas las naciones civilizadas "cuyos productos y utensilios son por lo general del mismo tipo o casi parecidos".

Aquel poder demiúrgico de la palabra como creadora - más que reproductora - de la realidad que está en los Génesis -en el judeocristiano, en el Popol-Vuh de la civilización maya-quiché, y en el babilónico Enuma Elish-se fortaleció con la escritura, al proyectar aquel efecto desde el momento de su primera enunciación a través del tiempo y el espacio, pero también se vio incrementado con la segunda gran revolución tecnológica al servicio de la lengua, la de la imprenta, y lo está haciendo de forma 
redoblada con los avances de nuestra era de la comunicación audiovisual digitalizada. Del sonido, a la voz; y de la voz a la letra manuscrita o proliferante gracias al invento de Johannes Gutenberg.

Siendo como es el asunto de la verdad tan antiguo como la Humanidad, adquiere no obstante nuevas y preocupantes dimensiones en la era posmoderna que vivimos, con su invención de la llamada realidad virtual y los prometidos desarrollos de la inteligencia artificial. Es evidente, por ejemplo, la proliferación de los bulos y patrañas (y de las fake-news) gracias a las múltiples posibilidades de comunicación entre individuos que proporciona la sociedad digital.

Recordando a Saussure (y a Aristóteles), fenómenos de tanta actualidad como la corrección política remiten también inexcusablemente a esas dos dimensiones del lenguaje que son la langue (el código o contrato social) y la parole (lo individual). Y las tensiones que les son conexas estaban ya previstas en la tercera obra de Aristóteles, junto a la Poética y la Retórica, que trata de eso mismo: el gran teatro del lenguaje. Leemos así, en el libro primero de la Política, que la razón de que el hombre sea un ser social, más que cualquier abeja y que cualquier otro animal gregario, es clara. La naturaleza no hace nada en vano. Solo el hombre, entre los animales, posee la palabra. Y añadía el Estagirita que la voz es una indicación del dolor y del placer; por eso la tienen también los otros animales. Pero -añade-la palabra existe para manifestar lo conveniente y lo dañino, así como lo justo y lo injusto. Y esto es lo propio de los humanos frente a los demás animales: poseer, de modo exclusivo, el sentido de lo bueno y lo malo, lo justo y lo injusto, y las demás apreciaciones.

Quiere ello decir que el idioma que usamos sirve para que requebremos y enamoremos, para que nos portemos bien, para que seamos educados. Pero también sirve para lo contrario: para ser canalla, injusto, grosero, machista.

Una manifestación de creciente incidencia en este terreno viene derivada precisamente de la corrección política y afecta a la naturaleza y contenido de los diccionarios. Pero sería inconcebible un diccionario solo de las palabras bonitas. Sería un diccionario censurado. Y a estas alturas no podemos permitir la censura. Cuando los fundadores de la Real Academia Española comenzaron a publicar en I726 su primer diccionario -el conocido como Diccionario de autoridades-, advertían en el prólogo que esa obra integrada aproximadamente por 33.000 lemas no contendría nombres propios (esto es razonable, porque los nombres propios pertenecen a las enciclopedias) y añadían: "Y tampoco aquellas palabras que designen desnudamente objeto indecente". Y, efectivamente, en el Diccionario de autoridades no hay palabras que designen los órganos o las prácticas sexuales, las cosas relacionadas con el cuerpo, la escatología. Era un diccionario con censura. ¿Hoy se admitiría esto? No, y tampoco podemos permitir que el Diccionario prescinda de determinados vocablos en función de que a un grupo les resulten ofensivos. Es una censura procedente de ese ente existente pero gaseoso que es la sociedad civil.

¿Dónde ponemos el límite? ¿Quién es el que decide que una palabra gusta o no gusta? Evidentemente, detrás de todo esto está el uso. Las Academias no inventan palabras desagradables y tampoco las promociona. Escribía con un punto de hipérbole el filósofo José Ortega y Gasset (I983 que en los diccionarios están todas las palabras de una lengua y, sin embargo, el autor de ellos es el único hombre que cuando las escribe no las dice. Cuando, con todo el escrúpulo de filólogo, anota los vocablos estúpido ('citrullo') o mamarracho ('bamboccio'), no los dice de nadie ni a nadie.

Porque la lengua expresa todo lo bueno y lo malo que hay en la realidad y en la persona. No crea, sin embargo, ni lo uno ni lo otro. Y lo hace no por el designio de alguien, de algún poder trascendental o personal que elige las palabras para hacer el bien o causar el daño. No se puede, pues, afirmar que el 
lenguaje se comporta injustamente, como se podría pensar si tenemos en cuenta algún caso concreto, como por ejemplo el del tratamiento en castellano (y no solo en esta lengua) que merece un animal tan amable como es el perro.

El movimiento del especismo hace ya medio siglo que clama contra la discriminación basada en la diferencia de especie entre los animales. Todo viene de un cierto antropocentrismo moral, que infravalora, cuando no desdeña, los derechos e intereses de los individuos que no son homines sapientes. Por eso adalides del poshumanismo como la filósofa feminista Rosi Braidotti (2013) hace suyo el término de carnofalologocentrismo puesto en circulación por Jacques Derrida para denunciar la violencia epistémica y material ejercida por el poder de la especie humana sobre los animales, y proclamar a los cuatro vientos su militancia en contra de la antropolatría, la arrogancia del Hombre como especie dominante cuya prepotencia justifica el acceso sin limitación alguna al cuerpo del animal que es, sin embargo, el "más necesario, familiar y precioso otro del anthropos".

Para Braidotti, la dimensión posthumana del postantropocentrismo representa una expresión más del movimiento deconstructivo. Significa la deconstrucción de la supremacía de nuestra especie, mediante la negación de toda idea estable y preponderante de la naturaleza humana, del antrhopos y el bios como "categóricamente distintos de la vida de los animales y no-humanos, o sea, de zoe".

En clave de la corrección política pensemos en cuál sería la respuesta al tratamiento de las voces relacionadas con el perro en el diccionario español por parte de una asociación cívica denominada, por ejemplo, "El mejor amigo del hombre" - o "El mejor amigo del perro", indistintamente -, que cargaría contra la segunda y tercera acepciones del lema principal como "persona despreciable" usada como insulto, o el mal o daño que se ocasiona a alguien al engañarle en un acuerdo o pacto.

Lo mismo sucede con la voz perrería, cuyas primeras acepciones están referidas tanto al conjunto o agregado de personas malvadas como a toda acción mala o inesperada contra alguien. La discriminación se hace todavía más cruda, dirían, si consideramos que para hombría se ofrece el significado de cualidad buena y destacada del hombre, especialmente la entereza o el valor. Hombrada es toda acción generosa y meritoria, mientras que perrada viene a definirse como acción villana que se comete faltando bajamente a la fe prometida o a la debida correspondencia.

Mondo cane. Lo cierto es que también en castellano perro adjetiva lo muy malo o indigno -"una vida perra", "muerte de perro", "noche perra"-, y en El Salvador dícese de personas enojadas o de genio áspero. No más benévolo es el repertorio sustantivo. La primera acepción de esta palabra prometía resultados mejores, pues después de la obligada referencia zoológica, afirma del perro que no solo tiene el olfato muy fino, sino que también es inteligente y muy leal al hombre. Hasta aquí todo va bien, pero enseguida irrumpen los problemas con el especismo. En la segunda acepción se alude ya a que las gentes de ciertas religiones usan perro para referirse, por afrenta y desdén, a los fieles que profesan otras; la tercera es, simplemente, persona despreciable, y también se define el nombre como el mal o daño que se ocasiona a alguien al engañarle en un acuerdo o pacto. Y así, coloquialmente la locución verbal dar perro a alguien significa 'causarle mal, daño o molestia al no cumplir lo acordado'". Tratar a alguien como un perro es tanto como maltratarlo o despreciarlo.

Llegados a este punto, y ante tanta injusticia léxica bien podríamos preguntarnos: ¿Por qué no perrería como "cualidad buena y destacada del perro, especialmente la fidelidad y el valor?" ¿Y carecería de sentido que una hombrada fuese también, como tantas veces de hecho lo es, toda acción propia de un hombre desalmado o ruin? Pero la realidad de la lengua castellana, fielmente recogida en el diccionario, no es esa. Y de acuerdo con el proceso colectivo e histórico de construcción del 
vocabulario de todos los idiomas, no podemos atribuir la responsabilidad concreta de esta manifiesta discriminación semántica hacia la raza canina a nadie, salvo al antropocentrismo que tratadistas como Mary Midgley (1978), la autora de Beast and Man: The Roots of Human Nature, prefiere denominar "Humanismo exclusivo", manifestación de un chovinismo humano carente de empatía hacia los animales, equiparable al chovinismo nacionalista, racista y sexista.

No es exactamente el caso de la corrección política actual, pero es cierto que a lo largo de la Historia ha habido numerosos ejemplos de injerencia en los términos de los idiomas por parte de los poderes políticos o religiosos institucionalizados. En Italia, está muy bien estudiado por autores como Giovanni Lazzari, Erasmo Leso, Elena Klein o Augusto Simonini este fenómeno en la era de Mussolini. Si calificásemos estas intervenciones del poder político como ejemplos de corrección política avant la lettre, extremo que no tengo nada claro pues creo que en primera instancia lo determinante es la injerencia de la sociedad civil, podríamos concluir que, por el fracaso que acompañó a la gran mayoría de ellas, es razonable vaticinar que algo parecido sucederá con las conminaciones a mordernos la lengua que menudean en nuestra posmodernidad.

Así por ejemplo, una vez promulgado en el año 3rz el Edicto de Milán por el que los dos emperadores, Constantino I el Grande y Licinio, reconocían el Cristianismo como religión oficial del Estado no tardó en manifestarse la oposición por parte de los clérigos a que los días de la semana siguieran identificándose con los nombres de los dioses paganos. A finales del siglo $\mathrm{V}$ fue especialmente beligerante contra esta circunstancia el obispo Cesáreo de Arlés, y en la centuria siguiente Martín de Braga.

Así, el primero clamaba porque "nullum diem daemonum appellatione dignum ese iudicemus, et nunquam dicamus diem martis, diem mercurii, diem iovis; sed priman et secundan vel tertiam feriam". Sus diocesanos, hablantes de un latín vulgar que estaba ya evolucionando hacia lo que sería el romance francés, hicieron sin embargo caso omiso de su reconvención, y acabaron confirmando el mardi, mercredi o jeudi, e incluso el todavía más perverso vendredi, el día venéreo (dies Veneris, dedicado a la diosa Venus). Más suerte tuvo, por el contrario, el prelado bracarense, dado que el portugués es la única lengua neolatina en la que los días de la semana se denominan segunda, terça, quarta, quinta y sexta feira. No existió problema, sin embargo, con el domingo, dies dominicus o "día del Señor", y el sábado, día "del descanso", procedente del hebreo šabāt.

No mayor suceso tuvieron en un empeño semejante al de los obispos medievales los revolucionarios franceses de 1789 . La Convención Nacional decretó un Calendier républicain que tuvo vigencia entre I792 y i806. Diseñado por un matemático, Gilbert Romme secundado por varios ilustres astrónomos, los nombres concretos para los meses salieron de la minerva del poeta Fabre d'Églantine: Germinal, Floreal y Pradial para la primavera; Mesidor, Termidor y Fructidor para el verano; Vendimiario, Brumario y Frimario para el otoño; y los meses invernales eran Nivoso, Pluvioso y Ventoso. Abolidas las semanas como unidades de cuenta, los meses se dividían en tres décadas de diez días (desde el primidi hasta el décadi), y para anular definitivamente la referencia al santoral cristiano a la hora de identificar cada día del año, tal y como hacía el calendario gregoriano, se recurría a la identificación con una planta (raisin...), un mineral (ardoise...), un animal (cochon...) o una herramienta (hoyau...).

Napoleón abolió este Calendrier républicain el i de enero de i8o6 (el día Argile del mes Nivôse), por conveniencia política (congraciarse con los católicos y el Papado) pero también pragmática (el resto de Europa y América seguía fiel al gregoriano). Con el derrocamiento del corso se restauró el calendario en I8I4, y también fue rescatado por la Comuna de Paris en i87i, pero ambos renacimientos fueron efímeros, y las sucesivas Repúblicas francesas acabaron por ignorar en este 
terreno aquel atisbo de corrección política intentado por la revolución primigenia.

Con tales antecedentes, no se puede ser excesivamente optimista acerca de la consagración de iniciativas semejantes de nuevo cuño posmoderno. Por ejemplo, la Calendaria que, arropada en inglés por el lema YES WOMEN CAN, la Unidad de igualdad y conciliación de la Universidad (española) de Granada propuso en 20I7. Los nombres de los doce meses son feminizados sin mayor dificultad; basta con sustituir la $\mathrm{O}$-réproba letra del abecedario que en su calidad de morfema gramatical del género masculino (e inclusivo) actúa como ariete del heteropatriarcado- por la A feminista: Enera, Febrera, Marza, Abrila, Maya, Junia, Julia, Agosta, Septiembra, Octubra, Noviembra y Diciembra. No resulta muy clarificadora la explicación que el director de la Unidad de Igualdad da para tan sorprendente empeño: "El machismo ha presentado la realidad como una incógnita con el objeto de quitarle el significado a cada día, a cada mes... a todos los años. No podemos caer en su trampa y presentar sus consecuencias como accidentes, porque son el resultado de todas las circunstancias que hacen que formen parte de ese siempre que nos ha acompañado a lo largo de la historia".

Y mencionado ya Bonaparte, de su mano viene a cuento el pensamiento del más brillante y cínico de los tratadistas políticos del Renacimiento, Niccolò Machiavelli, a propósito de la mentira y el nihil novum sub sole.

No tienen desperdicio los comentarios a pie de página, lacónicos y sucintos, que el emperador francés escribió en su ejemplar de Il príncipe. Que la mentira forma parte de los recursos propios de la práctica política Nicolás Maquiavelo ( $\mathrm{I}_{5} \mathrm{I}_{3}$ ) lo deja muy claro. Allí no tiene empacho en afirmar que un gobernante prudente no puede ni debe mantener la palabra dada cuando tal cumplimiento redunda en perjuicio propio y cuando han desaparecido ya los motivos que le obligaron a darla. Napoleón apostilla: "No hay otro partido que tomar".

No le faltarán, además, al imperante razones legítimas con las que disimular su inobservancia de lo prometido (y Bonaparte remacha: "Tengo hombres ingeniosos para ello"). El que manda debe ser un gran simulador y disimulador. Y concluye Maquiavelo con una máxima que sigue siendo de plena aplicación hoy en día: las personas somos tan crédulas y estamos tan condicionadas por las urgencias cotidianas que el que engaña encontrará siempre quien se deje engañar.

Esta última aseveración maquiavélica es suscrita por el exitoso político y militar francés, para quien "el mundo está compuesto de necios; entre la multitud esencialmente crédula, se contarán poquísimas gentes que duden, y ellas no se atreverán a decirlo".

Un ejemplo literario de esto lo encontramos en el relato de "Frate Cipolla", el último de la sexta jornada de Il Decamerone de Bocaccio que sin duda Maquiavelo leyó. Este fray Cebolla vive de exponer a los fieles por pueblos y aldeas falsas reliquias, como por ejemplo una pluma de sus alas que el arcángel san Gabriel perdiera cuando el trance de la Anunciación. Dos botarates amigos suyos, para burlarlo, se la roban y la sustituyen por carbones. Pero con descaro y suma habilidad retórica, el clérigo los presenta a su encandilado auditorio como los carbones con los que "fue asado el bienaventurado mártir San Lorenzo". Y la stolta moltitudine se volcó en pedir que los tocase con la inverosímil reliquia dándole en agradecimiento por ello mayores limosnas que nunca antes.

Aquellas reflexiones en las que coinciden Maquiavelo y Bonaparte suscitan un tema lúcidamente desarrollado por un riguroso coetáneo del florentino, Erasmo de Rotterdam, en una obra precedida por la Stultifera Navis alemana que Sebastian Brant había publicado ya en I494.

En términos de la pragmática lingüística, aquella disciplina que trata del funcionamiento del discurso 
en relación al que lo pronuncia y a quien lo recibe, y al contexto de ambos, la afirmación de Maquiavelo hecha suya por el corso equivale a decir que los actos ilocutivos producidos por ejemplo en un mitin político son aserciones exentas del requisito de la verificación.

Muchos electores quieren ser engañados; más aún, negarían sus votos al candidato que les dijese la verdad si esta es contraria a sus prejuicios; a lo que, como veremos con más detalle al tratar de la posverdad, los psicólogos sociales denominan "sesgo de confirmación" o "sesgo confirmatorio", actitud consistente en la tendencia a favorecer, buscar, interpretar, y recordar la información que confirma las propias creencias rechazando todas las posibles alternativas. También implica interpretar que las pruebas ambiguas apoyan la postura preexistente. El éxito de ese profeta de la post-truth que es Donald Trump da razón de esta paradoja de votar a sabiendas a favor de su posverdad.

También fueron coetáneos Napoleón Bonaparte y el Marqués de Condorcet, un aristócrata de la Ilustración elogiado por Voltaire como "filósofo universal" que desde sus convicciones racionalistas hizo suya la causa de la revolución de I789 y actuó como secretario de la Asamblea legislativa para la que llegó a redactar un borrador de Constitución.

En relación al tema de la mentira política, Nicolás de Condorcet se sitúa en las antípodas de Maquiavelo (y Napoleón). En I79o publica un opúsculo en el que trata sobre la conveniencia o no de engañar al pueblo, con lo que afronta un dilema que al florentino no le planteaba el más mínimo problema de conciencia. Su origen está en la noción de la "mentira piadosa" o "mentira noble" que Platón describe en La República como aquella que, administrada por los que mandan, puede contribuir a la paz social, el buen gobierno y la felicidad de la ciudadanía.

Deslumbrado sin duda el Marqués por la potencia de las Luces de la Razón, incurre en la ingenuidad de afirmar tajantemente que "los hombres no nacen estúpidos ni locos", y que en consecuencia "la voluntad de la mayoría estará siempre de acuerdo con la razón". Igualmente, sostiene que la verdad, y no ningún tipo de mentira, "es útil para el pueblo". Las leyes, los libros y la educación son garantes del "restablecimiento de la verdad", porque Condorcet advierte ya preocupantes síntomas de que parece no haber "ninguna verdad claramente definida sobre ningún argumento posible, o bien todo aquello que se cree es completamente falso". El triunfo y el progreso de la verdad depende, en definitiva, del "libre juicio de los hombres ilustrados".

A propósito de la posverdad actual, no faltan voces para afirman que no se trata de una forma de verdad, sino que es simplemente la mentira de toda la vida. La posverdad obedece a los designios de una época y una sociedad marcada por la quiebra de la Racionalidad y el rechazo indiscriminado hacia todo lo que representó en la Historia - no solo de Occidente - el Siglo de las Luces. La ya citada Rosi Baidotti, inspirándose expresamente en Derrida y Michel Foucault, se declara firme defensora del «postantropocentrismo posthumanista», y denuncia algunos de los presupuestos fundamentales de la Ilustración, entre ellos la idea del progreso de la humanidad «a través del uso autorregulador y teleológicamente orientado de la razón y la racionalidad científica laica, que se suponían vueltas a la perfectibilidad del Hombre». Precisamente aquello en lo que creía a pies juntillas Marie-Jean-Antoine Nicolas de Caritat, marqués de Condorcet.

Con anterioridad, ya en los salones de la Francia del preciosismo, muchos de ellos alentados por mujeres cultas e influyentes como la marquesa de Rambouillet o Madeleine de Scudéry, se debatía sobre la mentira, el disimulo y la sinceridad. Igualmente, al principio del siglo de la Razón se publicó en Inglaterra El arte de la mentira política, que circulará profusamente en francés a partir de I773 en edición publicada en Amsterdam. Su atribución a Jonathan Swift fue desde un principio apócrifa, y el 
acceso póstumo a su correspondencia en 1784 aclaró definitivamente la superchería.

Lo que sí resulta cierto es que con anterioridad el escritor irlandés había intervenido en una polémica para hacer valer su convicción de que, dada "la natural propensión del hombre a mentir y las muchedumbres a creer", la máxima comúnmente aceptada de que la verdad siempre se impone era insostenible. Ya Plutarco, en Iside et Osiride, proclamaba que ni Dios puede dar, ni el hombre recibir nada más excelente que la verdad. En ello creía a pies juntillas Miguel de Cervantes, según, entre otras ocasiones, manifiesta en El Quijote ("La verdad adelgaza y no quiebra, y siempre anda sobre la mentira, como el aceite sobre el agua") y en Los trabajos de Persiles y Sigismunda: «La verdad bien puede enfermar, pero no morir del todo». Tales convicciones las ratificaba enfáticamente el candidato a la presidencia del gobierno español Pedro Sánchez en el debate televisivo prelectoral de 4 de noviembre de 2019: "No hay nada hay más fuerte que la verdad. No hay nada más fuerte que la verdad. Y yo por eso pido llanamente el voto".

En realidad, el verdadero autor de The Art of Political Lying había sido el escocés John Arbuthnot, médico de la reina Ana y ferviente admirador del estilo satírico de Swift. Es muy interesante comparar sus ideas de ilustrado británico con las del humanista Maquiavelo. Ambos reflexionan acerca del arte de mentir en política, una pseudología que, muy en el registro del Despotismo ilustrado, le parece a Arbuthnot "el arte de hacer crer al pueblo falsedades saludables y hacerlo a buen fin", en la estela, evidentemente, de Platón. La diferencia entre el florentino y el escocés es clara: para el primero, mentir era legítimo como una estrategia imprescindible para el ejercicio competente y eficaz del poder; para el segundo, la legitimidad de la mentira política radicaba en el principio del "todo para el pueblo pero sin el pueblo". Según Arbuthnot, la gente del común no tenía derecho alguno a conocer la verdad de la práctica gubernativa, como tampoco lo tenía "a pretender poseer grandes patrimonios, tierras o casas señoriales".

En un escenario ideológico, histórico y cultural muy distinto, ya a finales del siglo XIX, resurgirá con fuerza el cinismo maquiavélico en torno al engaño de la verdad con el diálogo literario sobre La decadencia de la mentira escrito por otro irlandés excéntrico al sistema de valores de la época victoriana, Oscar Wilde (I898).

El debate que mantienen en una casa de campo de Nottinghamshire Cyril y Vivian trata en principio de literatura, de la preeminencia en sus creaciones de la realidad o la ficción. Por boca de Vivian, el autor de la Balada de la cárcel de Reading expresa su absoluta inclinación hacia el Arte por el Arte, a la búsqueda exclusiva de la Belleza a través de la creación literaria, y su desprecio hacia el realismo perseguido por la novela francesa de un Émile Zola, cuyo método de trabajo le parece que conduce a un "absoluto fracaso".

Pero cuando, alejándose por un momento de sus discusiones literarias, Cyril menciona a los políticos como eficaces cultivadores del arte de la mentira, su interlocutor protesta pues no ve en ninguno de ellos las virtudes del auténtico mentiroso, "con sus aseveraciones desvergonzadas y atrevidas, su espléndida irresponsabilidad y su sano desprecio natural por cualquier tipo de prueba".

La brillantez de su cinismo lo lleva a denunciar que incluso los periódicos "han degenerado y en la actualidad uno puede fiarse ciegamente de ellos". Más allá del verismo de las novelas que pretenden emular a la realidad, desafortunadamente parece triunfar "la mórbida y malsana facultad de decir la verdad", una "monstruosa devoción por los hechos". Y en especial le repugna el que los Estados Unidos hubiesen adoptado como héroe nacional a un hombre (George Washington) "que, según él mismo confesaba, era incapaz de decir una mentira". 
Vivian, sosias del propio Wilde a estos efectos, echa en falta al "mentiroso culto y cautivador", "el auténtico pilar de la sociedad civilizada". Como arquetipo del anti- George Washington, primer presidente de los Estados Unidos, bien podría servirnos el cuadragésimo quinto, al que hemos calificado ya como «apóstol de la post-truth». Pero ¡qué difícil resulta identificarlo con el mentiroso culto y cautivador de Oscar Wilde! A pesar de que a veces, cuando reflexionamos sobre sus salidas de tono y sus actuaciones desaforadas, se nos ocurre pensar temerariamente en que pueda ser lector de Orwell, Foucault o Derrida.

Saltando de mi interés por los orígenes de la posverdad a otra de mis preocupaciones cual es la corrección política, y continuando en la línea de las ideaciones peregrinas, a veces doy en pensar que un buen ejemplo de esa forma de eufemismo censorial tan en boga en nuestra posmodernidad la podemos encontrar en la traducción al castellano del título Enchomion Moriae seu Laus Stultitiae de Erasmo de Rotterdam, texto prácticamente coetáneo de El Príncipe de Maquiavelo que lo escribió en I5I3, dos años después de que el filósofo y teólogo neerlandés publicara el suyo.

Desde su primera edición en castellano, y así hasta hoy, la obra es conocida en nuestra lengua como Elogio de la locura, cuando es patente que tanto en griego como en latín el autor avisa de que va a tratar de la necedad o estulticia. ¿Pensó nuestro primer traductor de Erasmo (I5II), y luego todos sus editores y nuevos traductores hasta hoy, que esa mención era políticamente incorrecta porque algunos podrían darse por aludidos? Aludidos y ofendidos; algo que con toda certeza no ocurriría con los orates, a los que, por otra parte, la sociedad hace desde siempre mucho menos caso que a los estúpidos.

Mas la lectura de las sesudas, irónicas, mordaces y valientes páginas erasmianas no deja lugar a dudas acerca de quiénes son el objeto de su atención, aunque el autor se cure en salud adelantando que no nombrará a nadie en concreto a la hora de pasar revista a las ridiculeces que ha registrado en determinados comportamientos humanos. Y esa prudencia le viene sugerida por un prurito muy extendido hoy: «la delicadeza de los oídos de nuestros días; casi no pueden escuchar sino los títulos aduladores».

Es la propia Necedad la que habla en primera persona para ponderar que, desde Sófocles, es comúnmente aceptado que la vida es más agradable no sabiendo absolutamente nada. No espera respuesta para esta pregunta retórica: $¿$ Hay alguien más feliz que esos hombres a quienes las gentes llaman estultos, necios, imbéciles y tontos, nombres que son a mi entender hermosísimos?".

Denunciaba Isaac Asimov a este respecto la falacia de pensar que la democracia debe asumir afırmaciones como "mi ignorancia es tan buena como tu conocimiento", algo que ya está en un verso del soneto 66 de Shakespeare al mencionar al necio que fingiéndose docto se atreve a juzgar el talento ("And folly, doctor like, controlling skill"). La actualidad de este la acreditan un libro de Tom Nichols (20I7) sobre la muerte del saber y un espléndido artículo de Antonio Muñoz Molina de título complementario, El regreso del conocimiento, publicado en el diario El País (25-III-2020), en donde el novelista y académico español hace algunas reflexiones al hilo de la pandemia provocada en todo el mundo por la Covid-rg. La calamidad de la peste nos ha hecho abrir los ojos ante "la importancia suprema del conocimiento sólido y preciso, para esforzarnos en separar los hechos de los bulos y de la fantasmagoría y distinguir con nitidez inmediata las voces de las personas que saben de verdad, las que merecen nuestra admiración". Y a la vez nos acongoja "habernos acostumbrado o resignado durante tanto tiempo al descrédito del saber, a la celebración de la impostura y la ignorancia".

Tom Nichols por su parte repara en la auténtica campaña contra el conocimiento establecido desde 
fuentes fiables, nacidas de la ciencia y del testimonio de los expertos, vicio que no es novedad de última hora, sino que ha estado jalonada como tal campaña por hitos programados al servicio de la política y los intereses económicos, muy próximos en sus estrategias y objetivos a los que son propios de la posverdad.

La exacerbación actual del science denialism, el negacionismo científico que intenta desautorizar las teorías que demuestran el cambio climático, la incidencia del tabaco en el cáncer, la eficacia de las vacunas o, incluso, la propia existencia de la pandemia provocada por el coronavirus tiene evidentemente mucho que ver con la proliferación democratizadora de la información a través de internet, con el empoderamiento de ciudadanos sin mayor cualificación formativa e intelectual que la que ellos se conceden a sí mismos, y con el desdén acomplejado -cuando no agresivo- hacia la competencia de quienes dedican su vida a la adquisición rigurosa del saber para comprender cabalmente la complejidad de nuestras realidades. No oculta Nichols la vinculación entre esta rebelión contra los sabios, tratados como una despreciable secta elitista, y sobresaltos políticos como el acceso de Donald Trump a la presidencia de los Estados Unidos y la extensión de los populismos. La bandera de esta rebelión lleva inscrito un lema rotundo: I'm as good as you.

En el tratado de Erasmo leemos también que si la Sabiduría consiste en seguir la Razón, la Necedad aconseja dejarse llevar por las pasiones. La Fortuna favorece a los necios. Los sabios son inútiles para los menesteres de la vida, y la Historia demuestra que los gobiernos más funestos han sido los que han estado en mano "de algún filosofastro o de algún aficionado a las letras". Pero si alguno de estos busca el éxito como escritor, cuantas más tonterías escriba más aplaudido será por la multitud de necios ignorantes, por esa "enorme y poderosa bestia que llamamos pueblo". E introduciéndose en el terreno propio de su coetáneo de la Florencia medicea, reconoce la Necedad que "gracias a mi auxilio", los reyes "dejan a los dioses" los exigentes cuidados de "ocuparse de los intereses comunes (...) y hacer la dicha del género humano" para darse ellos "a la buena vida" y no escuchar "más que a quienes les hablan de cosas divertidas por no ser turbado en su ánimo". Por supuesto, en sintonía con Maquiavelo la propia Necedad afirma que "los reyes no aman la verdad". Precisamente, la voz protagonista del Eclesiastés bíblico, que Erasmo aduce como autoridad para fundamentar sus tesis, el rey de Israel Cohelet, hijo de David, admitía que "en muchedumbre de sciencia, mucha saña; y el que añade sabiduría, añade dolor". Cierto que el sabio tiene ojos en la frente y el necio anda en tinieblas, pero una misma será la suerte de ambos, y en definitiva morirá el sabio igual que el necio.

La impronta del mal titulado en español Elogio de la necedad siguió vigente hasta hoy. En una carta de I754 a la ilustrada Madame du Deffand el mismo Voltaire pontificaba que si no hay personas completamente inteligentes, si las hay completamente mentecatas, y que él y la dama nunca llegarían a ser tan felices como los cenutrios. Afirmaba asimismo Bertrand Russell que el problema con los ignorantes es que están siempre seguros, y los discretos, en cambio, llenos de dudas. Además, aquellos cuentan en la sociedad digital con un sinfín de posibilidades y artilugios para difundir globalmente sus simplezas o necedades.

Por su parte, el novelista inglés Martin Amis (I986), en un libro cuyo título - The Moronic Inferno- le fue sugerido por Saul Bellow, recuerda que este y Gore Vidal coincidían en el convencimiento de que en su país, los Estados Unidos, «la estupidez es profundamente reverenciada», y eso que todavía no había sobrevenido la presidencia trumpiana. Amis sí que escribe, con la mirada perspectivística de un inglés oxoniense, desde el conocimiento directo de Reagan y George W. Bush. Reconoce que el primero de ellos sabía hablar y actuar fotogénicamente ante las cámaras, pero su entronización anunciaba el triunfo de líderes mediocres que harían de Gerald Ford "un Bismarck, un Napoleón, un Alejandro". Y para explicar semejante depauperación, aducía que el electorado norteamericano iba a 
votar directamente desde su poltrona televisiva. Ya lo había vaticinado Gore Vidal cuando cubría periodísticamente una convención republicana en 1968: a medida que se afianzase la era de la televisión, los Reagan serían la norma, no la excepción.

Igualmente, se ha atrevido a estudiar este fenómeno, intemporal, ucrónico y utópico del que se ocupara Erasmo de Rotterdam Carlo Cipolla (I988) quien, con una metodología no ajena a su condición de profesor universitario de economía y una clara inspiración en la filosofía utilitarista de Jeremy Bentham, traza las cinco leyes fundamentales de la estupidez humana.

Según este catedrático de Pavía y de Berkeley, por lo general se infravalora el número de estúpidos que andan por el mundo adelante. La probabilidad de que una persona incurra en esta condición es independiente de cualquier otra de sus características personales. Los tales se caracterizan por causar pérdidas o daños a los demás sin beneficio propio, o incluso perjudicándose a sí mismos. Infravaloramos, además, su poder dañino. Y sin embargo, la persona estulta encierra un peligro máximo. Añadiré por mi parte: la estulticia interviene, de una u otra manera, en el terreno de la posverdad y la corrección política del que nos ocupamos, causando un daño insoportable a la sociedad y a las lenguas que la sustentan.

Ya en el contexto actual de la posmodernidad líquida, el poshumanismo y la inteligencia emocional, Ricardo Moreno Castillo (20I8) ha publicado un breve tratado sobre la estupidez humana, en el que sagazmente propone como una de las muestras más palmarias de ella la «obsesión por no incurrir en un lenguaje políticamente incorrecto"» afirmación en la que coincide, su prologuista Francesc de Carreras. Por su parte, el académico Juan Luis Cebrián acaba de publicar en España un libro que trata de la actualidad de nuestro país y se titula, sin morderse la lengua, Caos. El poder de los idiotas.

Y cumple, además, tener en cuenta otro factor relevante. Me refiero a la incidencia de las nuevas tecnologías de una información y comunicación proliferantes hasta extremos antaño inconcebibles en la omnipresencia de la estulticia. Así lo señala Andreu Jaume en un ensayo compilado por Jordi Ibáñez Fanés (2017): si la Ilustración soñaba con un mundo universalmente educado en la Razón, nuestra pesadilla posmoderna consiste en una aldea global hipercomunicada "donde la estupidez humana nunca había sido tan visible y rentable como ahora".

Dándole la vuelta a la confusión producida en torno al título de Erasmo de Rotterdam, Pape Satán aleppe, la última compilación de sus artículos de prensa que Umberto Eco (20r6) preparó poco antes de morir, incluye un capítulo titulado precisamente "De la estupidez a la locura" donde, con la brillante ironía que lo caracterizaba, se atreve a "cuantificar el número de los necios: son zoo millones como mínimo", sobre la base de que la Wikipedia había perdido esa misma cifra de usuarios y Eco los identificaba con navegantes que preferían estar en línea desbarrando con sus iguales a buscar informaciones enciclopédicas.

Gracias también al admirado semiólogo italiano tuve noticia del anuncio en internet de una Scientific and Technical University for Politically Intelligent Development, indentificada por el acrónimo STUPID. En su web se dan datos sobre la organización de su campus, en donde por el prurito de la diversidad sus señales y letreros para orientar el tráfico están en cinco lenguas y en braille. Entre los cursos ofrecidos se incluye, por caso, el dedicado a la contribución de los aborígenes de Australia y los indios de las Aleutianas a la mecánica cuántica, o cómo el ser vertically challenged favoreció la creatividad de investigadores como Einstein, Newton o Galileo. Desde la cosmología feminista, el Bing-bang tiene claras connotaciones eyaculatorias, por lo que la teoría alternativa es la del gentle nurturing, que explica el nacimiento del universo no por una explosión falocrática sino por una suave y demorada 
gestación. Pero esta última referencia nos llevaría muy lejos; nos reclamaría una reflexión sobre la problemática de la corrección política y el llamado "sexismo lingüístico" cuyo debate en Italia he seguido a través de obras como las compiladas por Alma Sabattini o Maria Serena Sapegno.

\section{Nota bibliografica:}

- Amis, Martin (1986): The Moronic Inferno and Other Visits to America, Londres, Jonathan Cape.

- Anónimo (1994): Enuma elish. Poema babilónico de la Creación, Madrid, Trotta.

- Anónimo (1993): El libro del Consejo (Popol Vuh), México, Universidad Nacional Autónoma de México ( $5^{\underline{a}}$ edición).

- Braidotti, Rosi (2015): Lo posthumano, Barcelona, Gedisa. Primera edición inglesa, 20r3.

- Brandt, Sebastian (2017): La nave de los necios, Madrid, Deloitte. Primera edición, I494.

- Cameron, Deborah (2012): Verbal Hygiene, Londres/Nueva York, Routledge. Primera edición inglesa, I995.

- Cebrián, Juan Luis (2020): Caos. El poder de los idiotas, Barcelona, Espasa.

- Cipolla, Carlo (2013): Las leyes fundamentales de la estupidez humana, Barcelona, Crítica. Primera edición italiana, 1988.

- Condorcet, Marqués de (2009): ¿Es conveniente engañar al pueblo?, Madrid, Ediciones Sequitur. Primera edición francesa, I790.

- Crisafulli, Edoardo (2004): Higiene verbale. Il políticamente corretto e la libertá lingüística, Florencia, Vallecchi Editore.

- Cusset, François (2003): French Theory. Foucault, Derrida, Deleuze \& Cie. Et les mutations de la vie intellectuelle aux États-Unis, Paris, Éditions La Découverte \& Syros.

- De Scudéry, Madeleine (20r7): Sobre la mentira, el disimulo y la sinceridad, Madrid, Siruela.

- Eco, Umberto (20r6): Pape Satán aleppe, Milán, La Nave di Teseo Editore.

- Erasmo da Rotterdam (I949): Elogio de la locura, Madrid, Aguilar. Primera edición latina, I5II.

- Golino, Enzo (20ro): Parola di Duce. Il linguaggio totalitario del fascismo e del nazismo, Milán, Rizzoli.

- Ibáñez Fanés, Jordi [compilador] (2017): En la era de la posverdad. 14 ensayos, Barcelona, Calambur Editorial.

- Klein, Gabriella (1982): La política lingüística del fascismo, Bolonia, Il Mulino.

- Lazzari, Giovanni (1975): Le parole del fascismo, Roma, Argileto.

- Leso, Erasmo, y otros (i977): La lingua italiana e il fascismo, Bolonia, Conzorzio Provinciale Pubblica Lettura.

- Maquiavelo, Nicolás (2010): El Príncipe, comentado por Napoleón Bonaparte, Madrid, Espasa. Primera edición italiana, I5I3.

- Moreno Castillo, Ricardo (2018): Breve tratado sobre la estupidez humana. Madrid, Fórcola.

- Nichols, Tom (2017): The Death of Expertise: The Campaign against Established Knowledge and Why it Matters, Nueva York, Oxford University Press.

- Ortega y Gasset, José (1983): El hombre y la gente, en Obras Completas, tomo VII, Madrid, Alianza Editorial/Revista de Occidente.

- Pintor, Luigi (200I): Políticamente scorretto: cronache di un quinquenio, 1996-2001, Turín, Bollati Boringhieri.

- Sabatini, Alma [compiladora] (ig93): Il sessismo nella lingua italiana, Roma, Istituto Poligrafico e Zacca dello Stato.

- Sapegno, Maria Serena [compiladora] (2010): Che genere di lingua? Sessismo e potere discriminatoriodelle parole, Roma, Carocci. 
- Simonini, Augusto (1978), Il linguaggio di Mussolini, Milán, Bompiani.

- Swift, Jonathan (2019), El arte de la mentira política, Madrid, Ediciones Sequitur. Primera edición francesa, I733.

- Vattimo, Gianni (1985), La fine della modernitá, Milán, Garzanti.

- Wilde, Oscar (2014), La decadencia de la mentira. Un comentario, Barcelona, Acantilado. Primera edición inglesa, 1898 .

\section{Cita come:}

Darío Villanueva, Mordersi la lingua. Corrección política y posverdad, "Italiano digitale", 2021, XVI, 2021/1 (gennaio-marzo)

DOI: $10.35948 / 2532-9006 / 2021.6517$

Copyright 2021 Accademia della Crusca

Pubblicato con licenza creative commons CC BY-NC-ND 